\title{
SPR Characteristics Curve and Distribution of Residual Stress in Self-Piercing Riveted Joints of Steel Sheets
}

\author{
Rezwanul Haque, ${ }^{1}$ Yat C. Wong, ${ }^{2}$ Anna Paradowska, ${ }^{3}$ \\ Stuart Blacket, ${ }^{4}$ and Yvonne Durandet ${ }^{2}$ \\ ${ }^{1}$ Faculty of Science, Health, Education and Engineering, University of the Sunshine Coast, Sippy Downs, QLD 4556, Australia \\ ${ }^{2}$ Faculty of Science, Engineering and Technology, Swinburne University of Technology, Hawthorn, VIC 3122, Australia \\ ${ }^{3}$ Australian Nuclear Science and Technology Organisation, Lucas Heights, NSW 2234, Australia \\ ${ }^{4}$ Henrob (UK) Pty Ltd, Geebung, QLD 4034, Australia
}

Correspondence should be addressed to Rezwanul Haque; rhaque@usc.edu.au

Received 10 October 2016; Revised 25 November 2016; Accepted 4 December 2016; Published 15 February 2017

Academic Editor: Paolo Ferro

Copyright (C) 2017 Rezwanul Haque et al. This is an open access article distributed under the Creative Commons Attribution License, which permits unrestricted use, distribution, and reproduction in any medium, provided the original work is properly cited.

Neutron diffraction was used to describe the residual stress distributions in self-piercing riveted (SPR) joints. The sheet material displayed a compressive residual stress near the joint, and the stress gradually became tensile in the sheet material far away from the joint. The stress in the rivet leg was lower in the thick joint of the softer steel sheet than in the thin joint of the harder steel sheet. This lower magnitude was attributed to the lower force gradient during the rivet flaring stage of the SPR process curve. This study shows how the residual stress results may be related to the physical occurrences that happened during joining, using the characteristics curve. The study also shows that neutron diffraction technique enabled a crack in the rivet tip to be detected which was not apparent from a cross-section.

\section{Introduction}

Self-piercing riveting (SPR) is a cold forming joining technique used to fasten sheet material by mechanical interlock. Automotive industries are increasingly adopting this technique because of the growing use of light weight or dissimilar metal (such as galvanized steel, aluminium, and magnesium alloys) that is difficult to weld. During SPR joining, a mechanical interlock is created between the sheets by flaring of the rivet in the bottom sheet under the guidance of rivet internal geometry and a die (Figure 1).

The SPR process is capable of joining multiple material stacks and dissimilar materials because of the formation of the mechanical interlock. However, the process requires plastic deformation of the rivet in the bottom sheet without cracking. The ability of a rivet to pierce and deform in a ductile manner becomes more limited with the introduction of higher strength lightweight materials.

Drossel and Jäckel [3] attempted to widen the operating window of SPR process for joining high strength low ductile materials by developing a new die. In their design, the sheet materials were superimposed with compressive stresses by a movable die during the SPR process. They were able to join aluminium die cast (AlSi9Mn) which has a limited elongation. He et al. [4, 5] reported joining of titanium, aluminium, and copper alloys. In addition, Meschut et al. [6] reported that more and more ultra-high strength materials and alloys are used in automotive industries, where limited deformation under load is required. To help optimize the SPR process for difficult materials and demanding applications, Finite Element Analysis (FEA) is required.

Bouchard et al. [7] conducted computational investigation of the behaviour of SPR joints in static and dynamic loading conditions. At first, they conducted a 2D simulation of the riveting process and then exported the $2 \mathrm{D}$ simulation outputs to a 3D model of the mechanical behaviour. They concluded that it is necessary to include plastic strain and residual stress developed during the SPR process in the 3D simulation for better prediction of the joint strength. A similar computational study was conducted by Grujicic et al. [8] to 

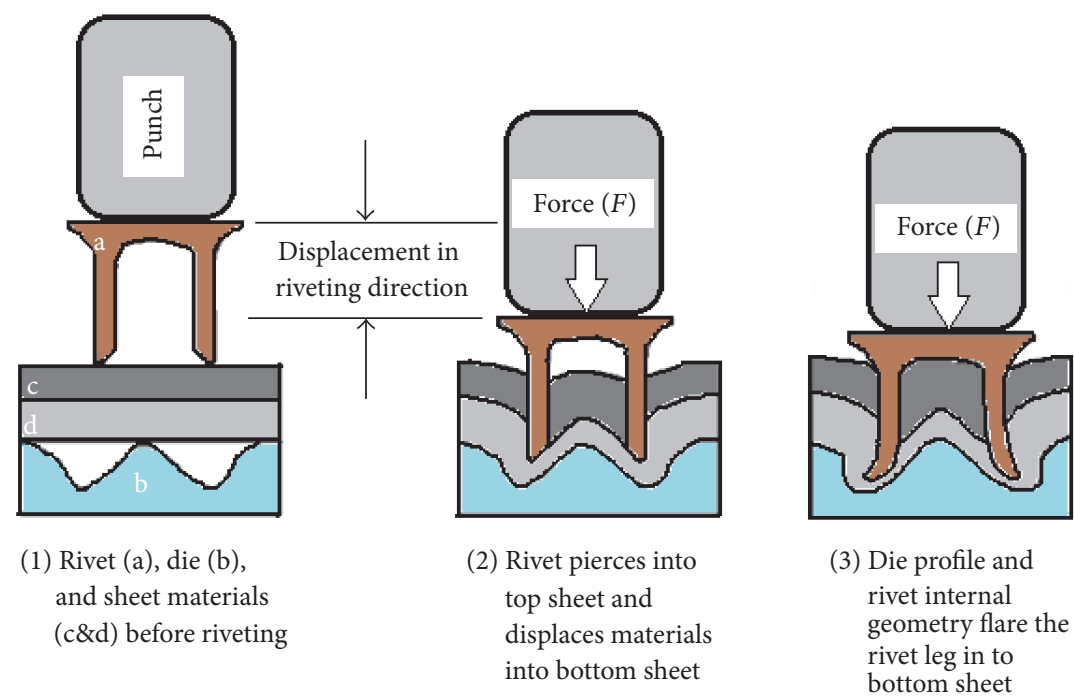

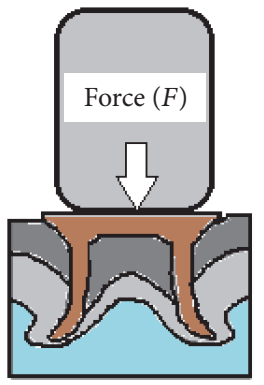

(4) Rivet head clamped on the top sheet and produces the joint

FIGURE 1: Graphical representation of the SPR joining, modified from $[1,2]$.

characterise the SPR joint behaviour as a function of different process variables. They also reached the conclusion that, in order to obtain the desired SPR joint mechanical properties, the plastic strain and residual stress state of both the rivet and sheet material should be included in the simulation. Porcaro et al. [9] investigated SPR joints in quasi-static loading using both numerical and experimental approaches. They performed the numerical simulation in two stages. At first, they performed FEA analysis of the riveting process and then they included the residual stress and local changes in material properties due to the riveting process in their 3D simulation of the mechanical behaviour. Good agreement was achieved between experimental and numerical simulation only when they included the residual stress due to the riveting operation in their 3D simulation. It should be noted that these residual stress values were obtained from the numerical simulation of the riveting process (first stage of their FEA), not from experimentally obtained values.

Sun and Khaleel [10] optimized the static performance of the riveted joint by increasing the rivet length. They used a $480 \mathrm{HV}$ rivet to join $2 \mathrm{~mm}$ AA5182-O (top sheet) $+1.6 \mathrm{~mm}$ DP600 (bottom sheet) with two different lengths (6 and $6.5 \mathrm{~mm}$ ). The joint strength was increased from 3.7 to $5.3 \mathrm{kN}$ with the $6.5 \mathrm{~mm}$ rivet. However, a long rivet requires more volume to be displaced, which can affect the residual stress developed inside the joint and ultimately affect the joint's performance in service.

FEA has been shown to be a useful tool to gain more understanding of the residual stress developed in the SPR process. Di Franco et al. [11] predicted the residual stress in SPR joints by FEA. The joints were produced using $1.5 \mathrm{~mm}$ carbon fibre and $1.3 \mathrm{~mm}$ basalt fibre reinforced plastics as top sheets and $2.7 \mathrm{~mm}$ thick aluminium (AA2024-T6) as bottom sheets and a rivet with a length of $6.5 \mathrm{~mm}$. The simulation results showed a high stress $(-1050 \mathrm{MPa})$ in the rivet but no validation was reported.
Swedish Institute for Metals Research (SIMR) performed a range of numerical simulations to predict residual strain and stress in ultra-high strength steel (UHSS) joints [1215]. Joining of UHSS (Hytens-1200, Hytens-800, and Trip800 ) of various thickness ( 1 and $2 \mathrm{~mm}$ ) was simulated. The magnitude of the stresses in the rivet was ranging from -1100 to $-1600 \mathrm{MPa}$. However, no experimental study was reported for validation of the high level of compressive residual stress.

Residual stress can also influence the fatigue performance of SPR joints. Li et al. [16] studied the fatigue performance of SPR joints of aluminium alloy considering 5 different edge distances $(5,6,8,11.5$, and $14.5 \mathrm{~mm})$, and with three or four values of load amplitude for each edge distances. They observed that, at low load amplitude, failure always occurred in the bottom sheet along the joint button. As the bottom sheet stretched in the die cavity during the SPR process, large residual stress/strain developed in the bottom sheet along the joint button. This large residual stress reduced the fatigue life of the bottom sheet around the joint button. They also concluded that crack initiation in the bottom sheet was caused by the local residual stress. However, no experimental values of residual stress/strain were reported.

Jin and Mallick [17] also studied the fatigue behaviour of SPR joints on aluminium alloy (5754-O) with six different thickness combinations $(1+1,1+2,1+3,2+2,2+3$, and $3+3 \mathrm{~mm}$ ). Fatigue testing was performed at $15 \mathrm{~Hz}$ and the load ratio was 0.1 with a variety of maximum fatigue stresses ranging from 53.3 to $95.9 \mathrm{MPa}$. They reported that the fatigue life can be improved by inducing a compressive residual stress around the rivet head by coining. The coining was conducted using a MTS servohydraulic machine with a circular groove of $0.5 \mathrm{~mm}$ width and two different inner diameters (10 and $12 \mathrm{~mm}$ ). Similarly, prestraining of material can also improve the fatigue performance. Han et al. [18] studied a joint of 2 $+2 \mathrm{~mm}$ NG 5754 joint (made with a $7 \mathrm{~mm}$ long rivet) and the materials were prestrained to three different levels $(3,5$, 
and $10 \%$ ). Fatigue was performed at $20 \mathrm{~Hz}$ with a maximum load ranging from $2.7 \mathrm{kN}$ to $4.5 \mathrm{kN}$. For each condition the minimum load was kept at $0.5 \mathrm{kN}$. They found that increasing prestraining led to better fatigue performance due to the reduction in the fretting scar. Similar result was found by Huang et al. [19] and Zhang et al. [20]: fatigue performance of SPR joint was significantly influenced by the residual stress developed during the plastic deformation of rivet and sheet materials. They studied the fatigue behaviour of SPR joints made up with aluminium, titanium, and copper alloys. They observed that fatigue performance of SPR joints can be improved by stress relief annealing.

To push the operating window of the SPR process it is necessary to gain more understanding of the deformation characteristics of the rivet and sheet materials in terms of residual stress. While FEA has been shown to be a useful tool to predict the residual stress and deformation of materials in the SPR process, the validation of most simulation studies reported in the literature [21] was shown by comparing the models output with the experimental force-displacement SPR process curves or cross sections of joints. There are few reports of residual stress measurements in the published literature.

A feasibility study on residual stress measurement in SPR joints by neutron diffraction was conducted by Haque et al. [22-24] for two different joints: aluminium-steel and steelsteel combinations. The authors showed that the nondestructive neutron diffraction technique successfully detected the position of the rivet leg and enabled variations in residual strain in the flared rivet in SPR joints to be measured. The same authors [25] conducted another study to characterise the residual stress in different joints of thick and strong sheets $(2.5 \mathrm{~mm}+2.5 \mathrm{~mm}$ steel, with yield strength of $450 \mathrm{MPa})$ and thin and soft sheets $(1.5 \mathrm{~mm}+1.5 \mathrm{~mm}$ steel, with a yield strength of $300 \mathrm{MPa}$ ). They found compressive residual stresses in the rivet. They also observed that the compressive residual stress in the rivet head was lower compared with the residual stress in the rivet leg.

The reason of conducting this study was to characterise the residual stress profiles in completely different SPR joint combinations and determine how they are related to the physical occurrences that happened during joining.

\section{Experimental Procedure}

2.1. Sample Preparation. The aim of this study was to understand how the SPR process curve may be related to residual stress in the joints. The two SPR joints were produced using semitubular rivets. The rivets' length was $3 \mathrm{~mm}$ greater than the joints' stack thickness. One joint was made with a thin $(1.5 \mathrm{~mm})$, hard $(270 \mathrm{HV})$ steel sheet and a hard $(480 \mathrm{HV})$ rivet. The other joint was made with a thicker $(2.5 \mathrm{~mm})$, softer $(198 \mathrm{HV})$ steel sheet and a harder $(555 \mathrm{HV})$ rivet. More details of the steel properties can be obtained from BlueScope website [26]. The joints parameters are summarized in Table 1.

Henrob's 2-stage hydraulic rivet setter with preclamp was used to produce the SPR joints while 250 bar was set as rivet setting pressure, and preclamp pressure was 130 bar.

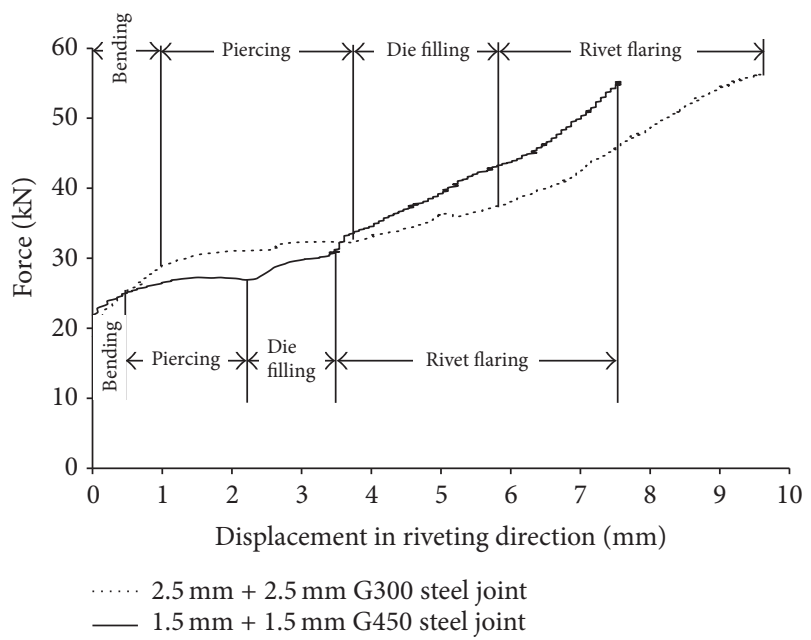

FIGURE 2: Physical events and SPR characteristics curves of the joints.

A linear variable differential transformer (LVDT), load cell, and pressure transducers were used to measure the punch displacement in riveting direction, force, rivet setting, and preclamp pressures, respectively, as a function of time.

Details on the experimental setup and method of producing the force-displacement curve and identifying the physical occurrences that happen during SPR are described in a previous study [27]. Figure 2 shows the characteristics curves for the SPR joints under investigation.

2.2. Residual Stress Measurement. Residual stress measurement by neutron diffraction was performed on the KOWARI Strain Scanner at the Australian Nuclear Science and Technology Organisation (ANSTO). Fe $\alpha$ (211) diffracting plane was selected and the incident beam was a monochromatic beam of thermal neutrons with wavelength of $1.67 \AA$. A 2D position sensitive ${ }^{3} \mathrm{He}$ detector recorded the diffraction peak. To utilize the Fe $\alpha$ (211) reflection, the detector was positioned at normal $\left(90^{\circ}\right.$ angle) to the incident beam. The experimental neutron diffraction setup is shown in Figure 3.

The present joint sample under investigation was small. Thus, to achieve an optimum condition with respect to experimental counting time and spatial resolution, $0.5 \times 0.5$ $\times 0.5 \mathrm{~mm}^{3}$ gauge volume was used. For accurate positioning $( \pm 100 \mu \mathrm{m})$ of the sample on the instrument, a positioning software SScanSS [28] was used. Acquisition time of 900 seconds for sheet material and 1500 seconds for rivet was chosen based on previous optimization work [29].

In the thin and hard steel joint I $(1.5 \mathrm{~mm}+1.5 \mathrm{~mm}$ G450 steel), residual strain components of three orthogonal directions (normal, transverse, and longitudinal) were measured at 5 points at the left side of the joint and 5 points at the right side of the joint along line AA (Figure 4(a)). These points were located at a distance of $1 \mathrm{~mm}$ starting from $-8.5 \mathrm{~mm}$ to $-4.5 \mathrm{~mm}$ on the left side and from $+4.5 \mathrm{~mm}$ to $+8.5 \mathrm{~mm}$ on the right side, Figure 4(a). Another 10 points were chosen along line $\mathrm{BB}$. To obtain the stress distribution 


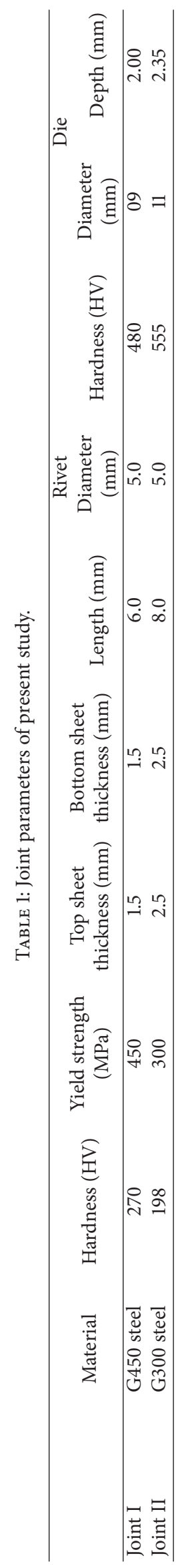




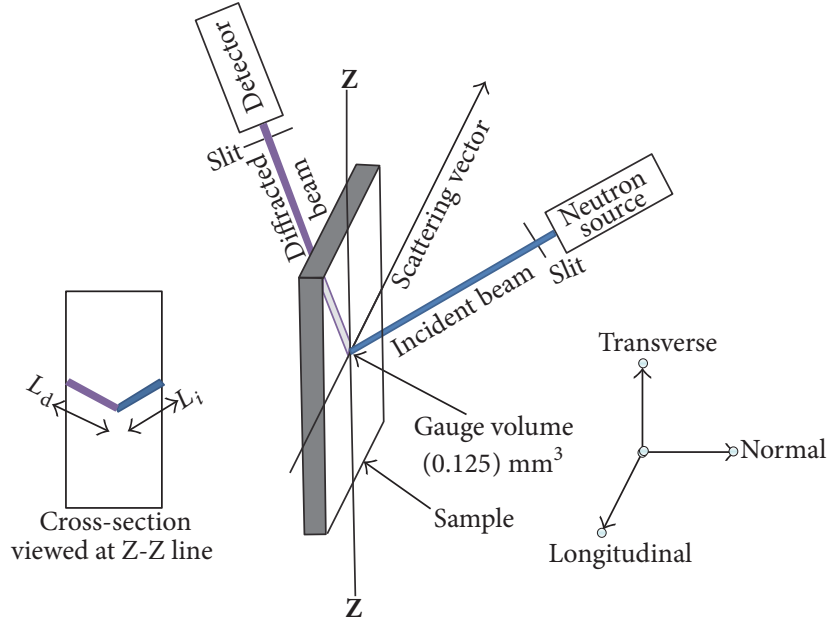

Incident neutron beam length $=L_{i} \quad$ Diffracted neutron beam length $=L_{d}$ Neutron path length $=L_{i}+L_{d}$

(a)

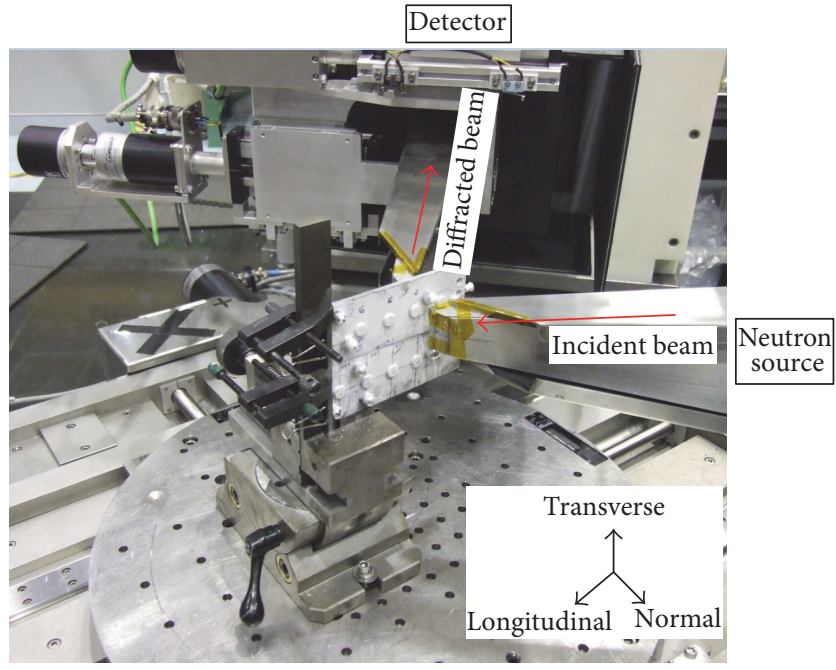

(b)

FIGURE 3: Strain measuring setup: (a) schematic and (b) experimental.

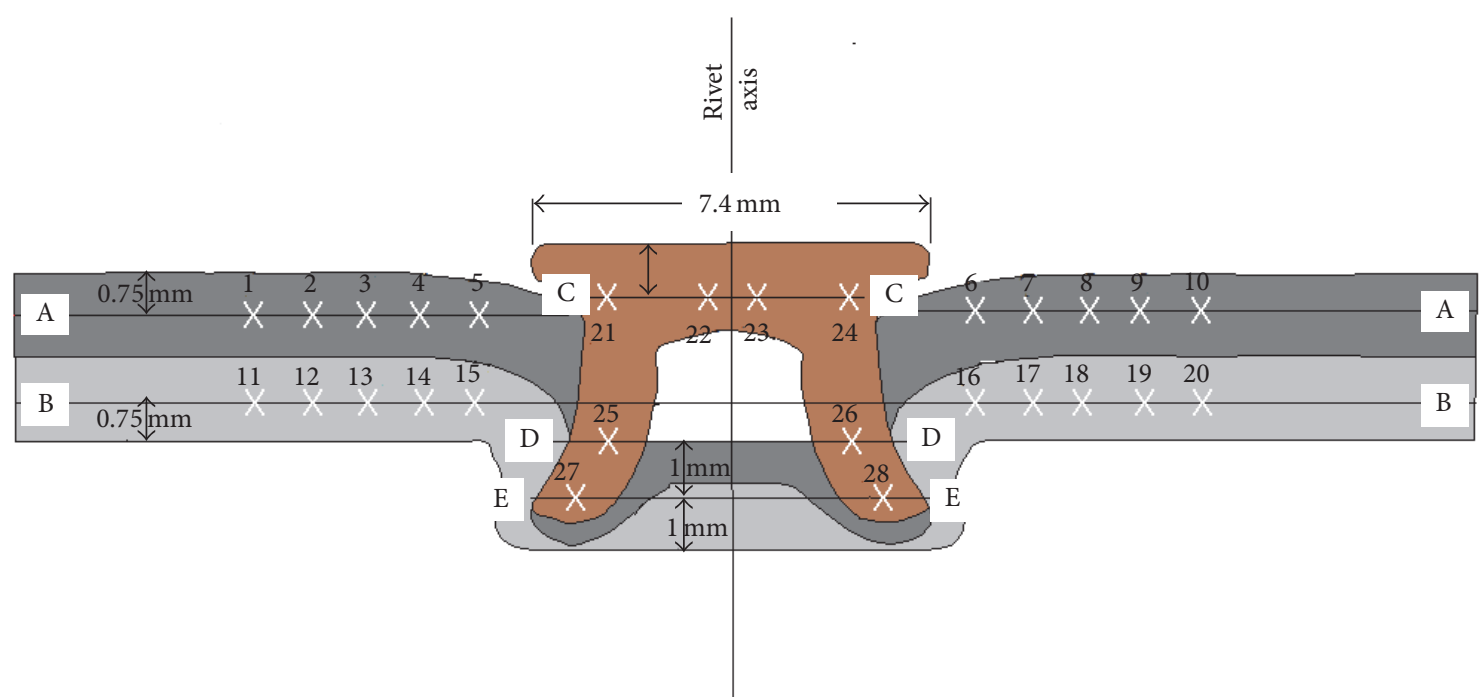

(a)

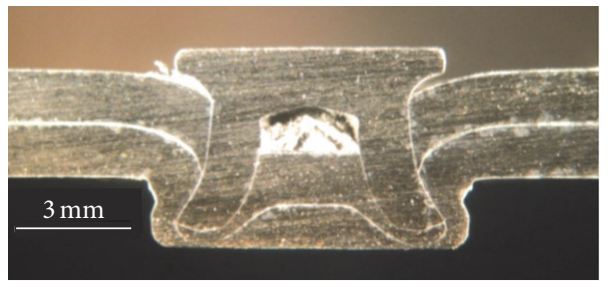

(b)

FIGURE 4: Joint I of Table 1: (a) residual stress measurement locations; (b) micrographic cross-section which was sectioned after conducting neutron diffraction experiments. 


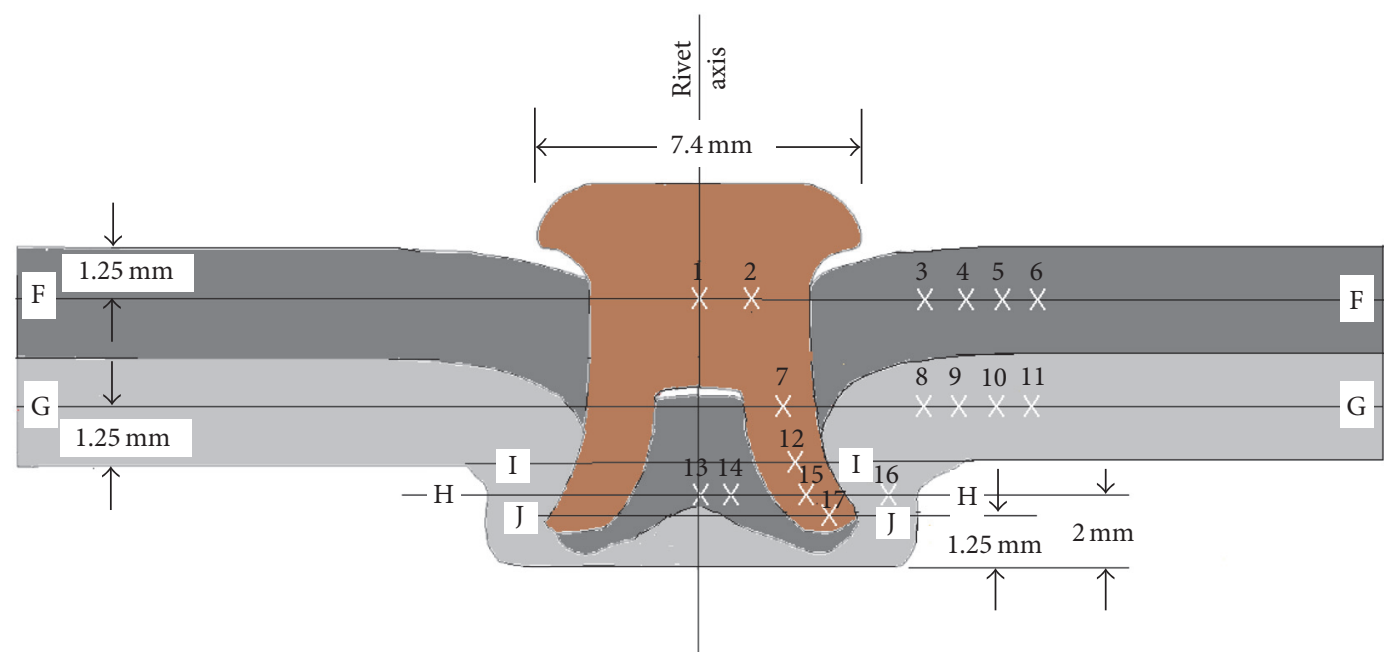

(a)

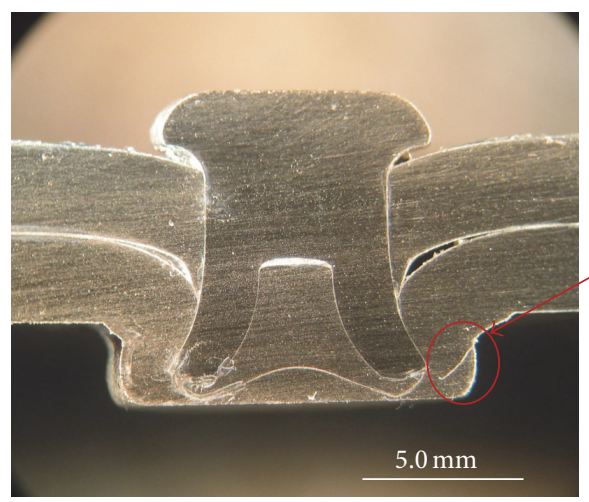

Crack in bottom

sheet

(b)

Figure 5: (a) Joint II of Table 1: (a) residual stress measurement locations; (b) micrographic cross-section which was sectioned after conducting neutron diffraction experiments.

in the rivet, 4 points along line $\mathrm{CC}$ and 2 points along lines $\mathrm{DD}$ and EE were chosen. All the measurement point locations along different lines are shown in Table 2. These points were selected to ensure that all the neutron counts through the specified gauge volume are coming from the desired material.

Joint II was made up with thick and soft steel $(2.5 \mathrm{~mm}$ $+2.5 \mathrm{~mm}$ G300 steel). To obtain the stress distribution in the sheet material, a sum of 11 measurement points was chosen. These points were shown in Figure 5(a) and they were located along lines FF, GG, and HH. Another 6 measurement points located along lines FF, II, JJ, and $\mathrm{HH}$ lines were chosen in order to obtain stress distribution in rivet. Table 3 shows the different measurement locations along these lines. In the case of joint II, it should be noted that strain was measured only on the right half from the rivet axis due to the limitations on the availability of neutron beam time at ANSTO.

Rivets are manufactured by forging and to achieve the required hardness level they were heat treated. As a result, in an as-supplied unused rivet, stress may exist. Therefore, to calculate microstrain, a lattice $d_{\mathrm{r}}$ (user reference) was used as an alternative of strain-free $\left(d_{0}\right)$ lattice. The reference lattice spacing $d_{\mathrm{r}}$ for the rivet material was determined from three point's average (two points in rivet leg and another one in rivet head) of an as-supplied unused rivet. The lattice $d_{\mathrm{r}}$ for the sheet material was taken from four points' average of a new sheet which were located at $1 \mathrm{~mm}$ from the four free corners. The values of the reference lattice $d_{\mathrm{r}}$ are summarized in Table 4.

The following equations were used to determine the strain and error [30]:

$$
\begin{aligned}
\varepsilon & =\frac{d}{d_{\mathrm{r}}}-1 \\
\Delta \varepsilon & =\sqrt{\left[\left\{\left(\frac{\partial \varepsilon}{\partial d}\right) \Delta d\right\}^{2}+\left\{\left(\frac{\partial \varepsilon}{\partial d_{\mathrm{r}}}\right) \Delta d_{\mathrm{r}}\right\}^{2}\right]} \\
& =\sqrt{\left[\left\{\frac{\Delta d}{d_{\mathrm{r}}}\right)^{2}+\left\{\frac{d * \Delta d_{\mathrm{r}}}{\left(d_{\mathrm{r}}\right)^{2}}\right\}^{2}\right]},
\end{aligned}
$$




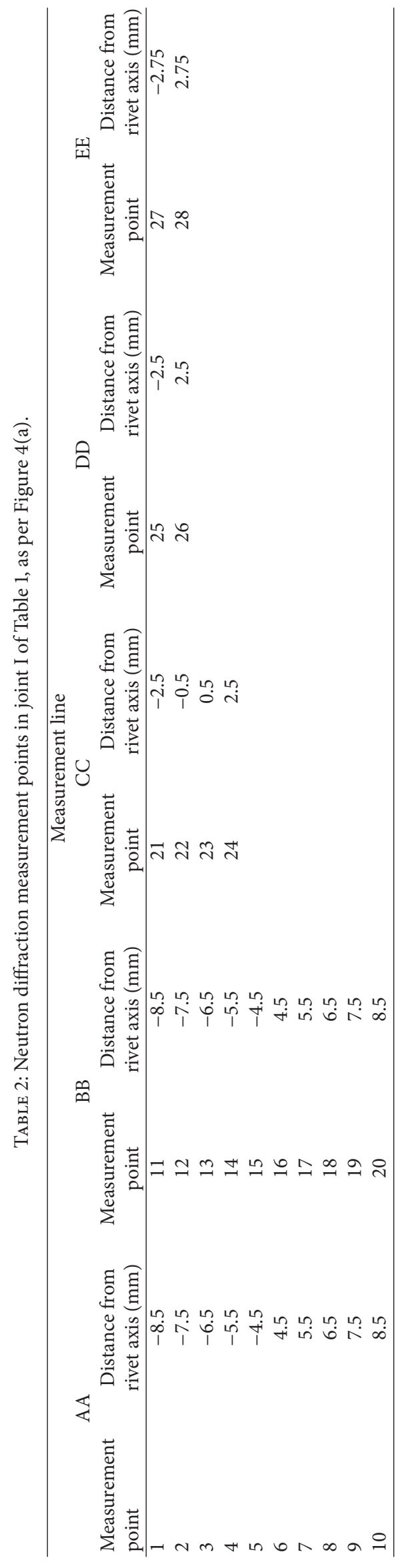




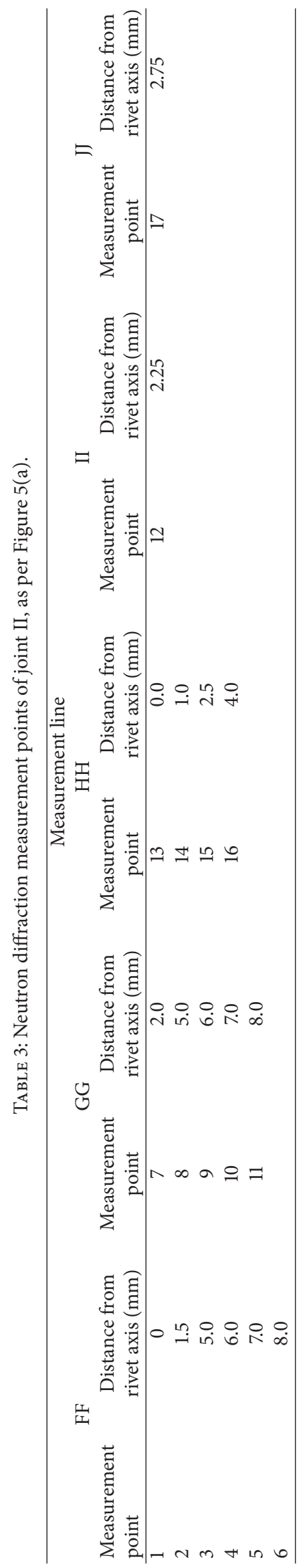


TABLE 4: Reference lattice spacing $d_{\mathrm{r}}$ of the sheets and rivets used to produce the selected joints.

\begin{tabular}{lcccr}
\hline & & Sheet material & \multicolumn{2}{c}{ Rivet } \\
& Name & Lattice spacing $(\AA)$ & Hardness & Lattice spacing $(\AA)$ \\
\hline Joint 1 & G450 steel & $1.16749473 \pm 9.19 \times 10^{-5}$ & $480 \mathrm{HV}$ & $1.16869423 \pm 18.25 \times 10^{-5}$ \\
Joint 2 & G300 steel & $1.16773361 \pm 8.39 \times 10^{-5}$ & $555 \mathrm{HV}$ & $1.16825497 \pm 30.12 \times 10^{-5}$ \\
\hline
\end{tabular}

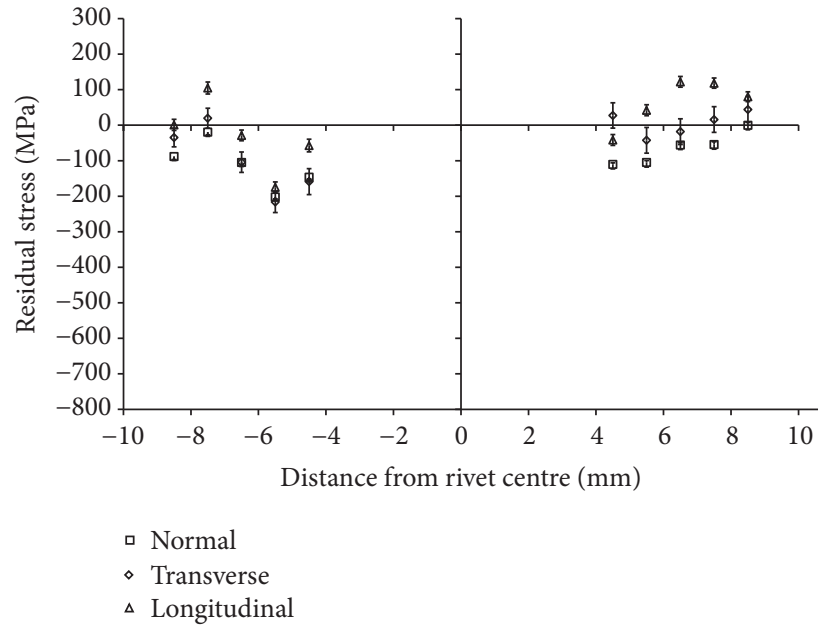

FIGURE 6: Distribution of residual in top sheet of joint I along AA line as depicted in Figure 4(a).

where $\varepsilon$ is measured strain and $d$ and $d_{\mathrm{r}}$ are lattice spacing and reference lattice spacing, respectively. $\Delta \varepsilon$ is the measurement error in strain. And, $\Delta d$ and $\Delta d_{\mathrm{r}}$ are also the measuring errors for lattice spacing and reference lattice spacing, respectively.

Finally, using the following formula residual stress was calculated [31]:

$$
\sigma_{i}=\frac{E}{(1+\nu)(1-2 * \nu)}\left[(1-\nu) * \varepsilon_{i}+\nu\left(\varepsilon_{j}+\varepsilon_{k}\right)\right],
$$

where $E(220 \mathrm{GPa})$ is the modulus of elasticity, $v(0.3)$ is the Poisson's ratio for rivet and steel material, and $i, j$, and $k$ denote three orthogonal directions.

\section{Results and Discussion}

3.1. Stress Distribution in Joint I of Table 1: $1.5 \mathrm{~mm}+1.5 \mathrm{~mm}$ G450 Steel (Thin) Joint. Figure 6 shows evaluated residual stresses in the top sheet located on line AA. A compressive behaviour was observed for the stresses near the rivet. However, stresses became tensile as they go far from the joint axis. It was clear from Figure 4 that the top sheet starts compressive bending toward the die cavity (by the clamping of the sheets between the nose of the rivet gun and die) at a distance of $6 \mathrm{~mm}$ from the rivet centre. Due to this bending, compressive residual stresses were observed in measurement points 4, 5, 6, and 7 along line AA which are situated between $-5.5 \mathrm{~mm}$ and $5.5 \mathrm{~mm}$ from the rivet axis. Tensile residual stresses at points $1,2,8,9$, and 10 (situated beyond $6.5 \mathrm{~mm}$ from the rivet axis) counterbalance the above-mentioned

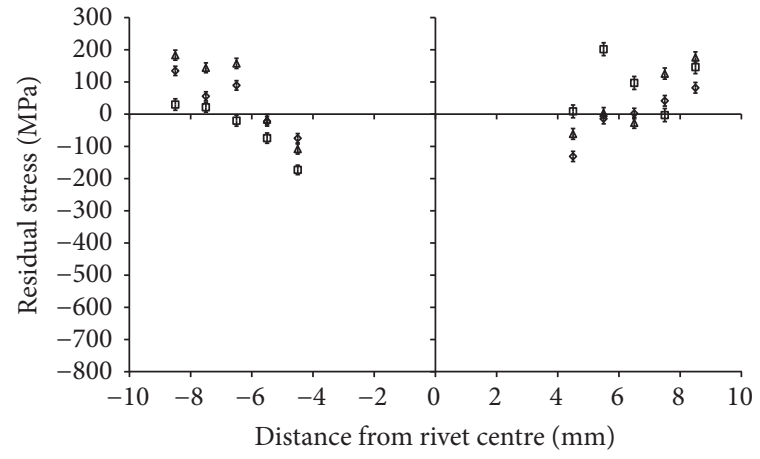

$$
\begin{aligned}
& \text { - Normal } \\
& \text { - Transverse } \\
& \Delta \text { Longitudinal }
\end{aligned}
$$

FIGURE 7: Distribution of residual in top sheet of joint I along BB line as depicted in Figure 4(a).

compressive stresses. Maximum tensile residual stress was observed in longitudinal direction at point $7(122 \pm 15 \mathrm{MPa})$ which was situated at $7.5 \mathrm{~mm}$ from the rivet centre on the right side of the joint. Minimum compressive residual stresses were observed at $5.5 \mathrm{~mm}$ from the rivet axis $(-201 \pm 11 \mathrm{MPa}$ in normal direction and $-216 \pm 15 \mathrm{MPa}$ in transverse direction at point 4 ). The overall stress distribution was symmetric.

The stresses in the bottom sheet (BB line) are presented in Figure 7. Like the top sheet, stress values were tensile away from the joint and compressive near the joint. However, compared with the top sheet, higher magnitude was observed for both tensile and compressive stresses in the bottom sheet. This is consistent with predictions made by Li et al. [16] that large value of stress/strain should occur in the bottom sheet as material is stretched inside the die cavity. Additionally, it is evident from Figure 4 that sharper bending occurred in the bottom sheet compared with the top sheet. Thus, higher tensile and compressive stresses were observed in the bottom sheet. A comparison of residual stress in longitudinal direction is shown in Figure 8. The maximum tensile stresses observed in longitudinal direction at the two extreme measurement points $( \pm 8.5 \mathrm{~mm}$ from rivet centre) were 186 $\pm 16 \mathrm{MPa}$ at location 11 and $176 \pm 17 \mathrm{MPa}$ at location 20 . Minimum compressive residual stress measured at location 15 (4.5 $\mathrm{mm}$ far of the rivet axis) in the normal direction had a magnitude of $-172 \pm 14 \mathrm{MPa}$. The overall stress distribution was again symmetrical.

Residual stresses which were measured in the rivet along lines CC, DD, and EE are presented in Figure 9. The stresses inside the rivet are compressive, reaching a value as high as 


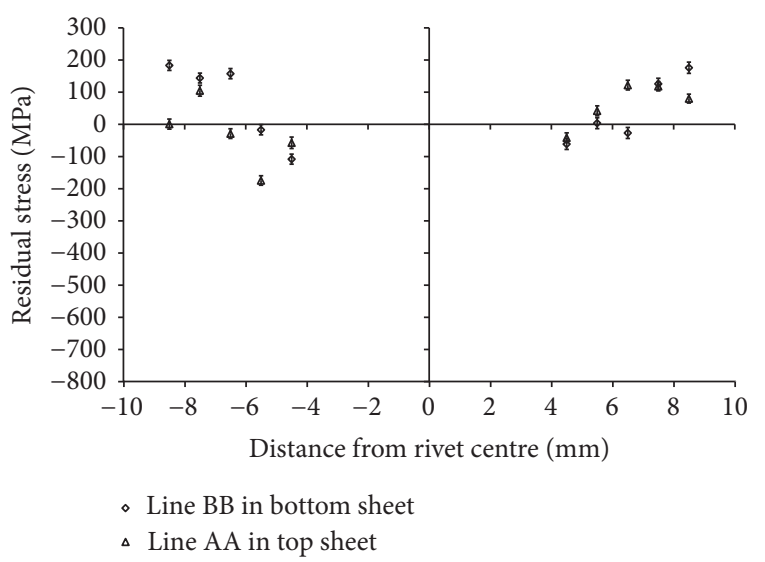

FIgURE 8: Comparison of residual stress distribution between top and bottom sheet of joint I in Table 1 (thin joint) along lines AA and $\mathrm{BB}$ according to the lines presented in Figure 4(a).

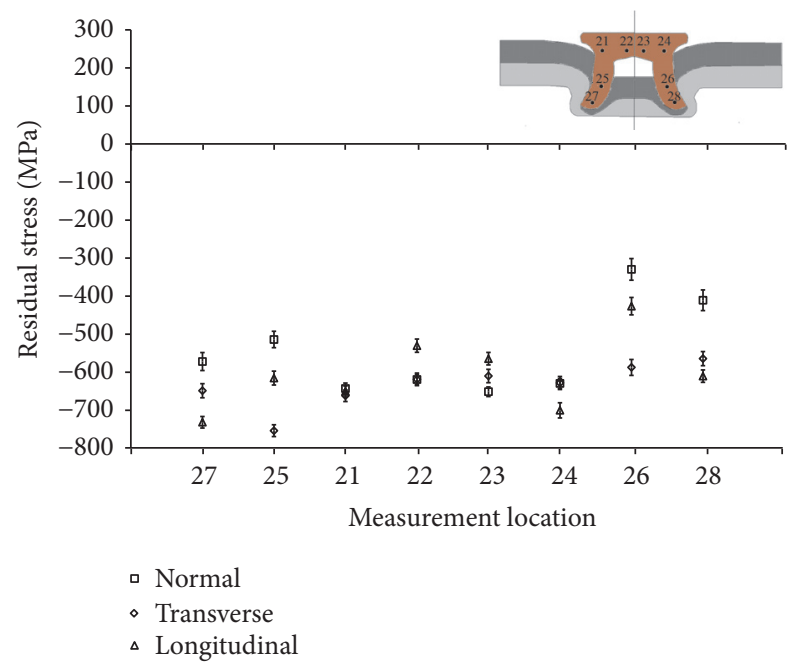

FIGURE 9: Distribution of residual stress in rivet for joint I of Table 1 (thin joint).

$-732 \pm 19 \mathrm{MPa}$. A huge amount of energy was imparted to a very small volume during the riveting process, enclosing the rivet within the sheets at high setting pressure, thereby forcing the rivet and the top and bottom sheets together and causing them to act as a single body. For this reason the measured stresses inside the rivet were compressive and this was counterbalanced by the stress distribution observed in the top and bottom sheets. Compressive stresses of measurement points 21, 22, 23, and 24 which were located on the rivet head were similar $(650 \pm 19 \mathrm{MPa})$. Stresses determined in the rivet leg were asymmetric due to the asymmetric C-frame deflection. The maximum compressive stress was observed at location number 25 (rivet leg on the left side) with a value of $-753 \pm 16 \mathrm{MPa}$ which was measured in the transverse direction.

The hardness ratio of 1.78 between rivet $(480 \mathrm{HV})$ and sheet materials $(270 \mathrm{HV})$ plays an important role in the residual stress profile inside the rivet. The higher the ratio, the lower the residual stress (in terms of magnitude) developed in the rivet. This experimental study (stresses ranging from $-530 \mathrm{MPa}$ to $-750 \mathrm{MPa}$ ) showed consistency with numerically predicted values $(-425 \mathrm{MPa}$ to $-765 \mathrm{MPa})$ stated for comparable positions in rivets [13].

It should be noted that the overall measurement error was lower in the steel sheet compared to those for the rivet. The diffraction peak was broader in the rivet than that from the sheets (see Figure 10). Also, the atomic structure of the rivet was martensitic. Thus, to achieve the desired accuracy $( \pm 50 \mu \mathrm{m} / \mu \mathrm{m})$ more neutron count was required as the measurement accuracy depends on the acquisition time [30]. In contrast, it was easy to detect the diffracted neutron peak in the top and bottom sheets whose ferritic microstructure yielded sharp neutron peaks (Figure 10). As a result, the residual strain/stress measured in the sheet material had a smaller error.

3.2. Stress Distribution in Joint II of Table 1: $2.5 \mathrm{~mm}+2.5 \mathrm{~mm}$ G300 Steel (Thick) Joint. Figure 11 shows evaluated residual stresses in the rivet and top sheet located on line FF. Unlike the previous joint, stresses in the top sheet material were found to be compressive. It is evident from Figure 5 that the top sheet started compressive bending in the die cavity at $8 \mathrm{~mm}$ distant from the rivet axis. A die with a large diameter $(11 \mathrm{~mm})$ was used to produce the joint compared with the previous joint ( $9 \mathrm{~mm}$ diameter die). Hence, the bending of the top sheet started at a distance of $8 \mathrm{~mm}$ from the riveting axis (it was $6 \mathrm{~mm}$ for the $1.5 \mathrm{~mm}+1.5 \mathrm{~mm}$ joint). It was expected that the residual stress would become tensile beyond the distance of $8 \mathrm{~mm}$ from the rivet axis, based on a previous study by Haque et al. [25] which showed that, in a joint of different materials but produced with the same die diameter, the stress in the top sheet turns out to be tensile at $9 \mathrm{~mm}$ far away from the rivet axis. Also, the stress would become negligible at a distance of three times of the rivet diameter [22]. Here, the maximum compressive residual stress in the top sheet $(-199 \pm 20 \mathrm{MPa})$ was observed at point 3 which was $5 \mathrm{~mm}$ distant from the rivet axis and the direction was transverse.

The residual stresses that were observed in the bottom sheet (Figure 12) showed a similar pattern. During the riveting process, the gradient of the force was low at the bending stage (Figure 2) for the thin joint. Thus, the amount of the compressive residual stresses in both the bottom and top sheets was lower in magnitude in the thin (joint I: $1.5 \mathrm{~mm}$ $+1.5 \mathrm{~mm}$ ) joint compared with the thick (joint II: $2.5 \mathrm{~mm}+$ $2.5 \mathrm{~mm}$ ) joint. Similar results were also obtained in different materials' combination as described in Haque et al. [25]. It is also evident from Figure 12 that the compressive residual stress was much higher at $2 \mathrm{~mm}$ away from the rivet axis compared with the other measurement locations, which indicates that this measurement location (point 7 along line GG as per Figure 5(a)) was in the rivet, and not in the bottom sheet. This result was verified with a cross-section (Figure 5(b)) which was made after the neutron diffraction measurement.

The material behaviour inside the die was obtained by evaluating the stress along line $\mathrm{HH}$. A compressive stress of 


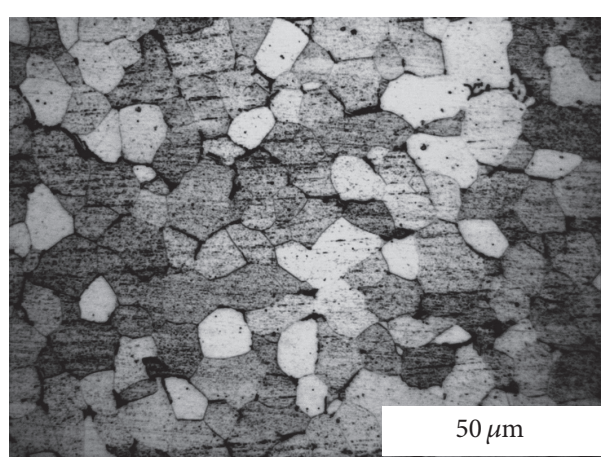

(a)

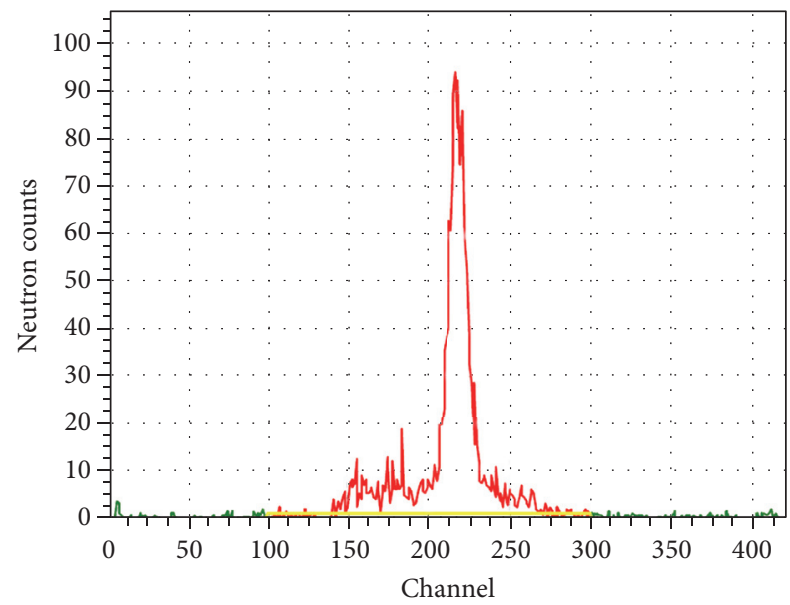

(c)

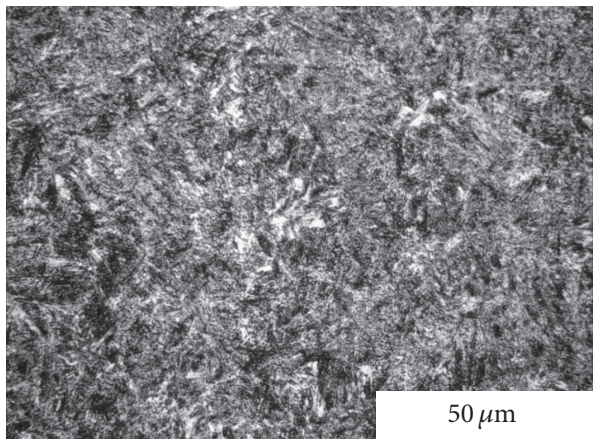

(b)

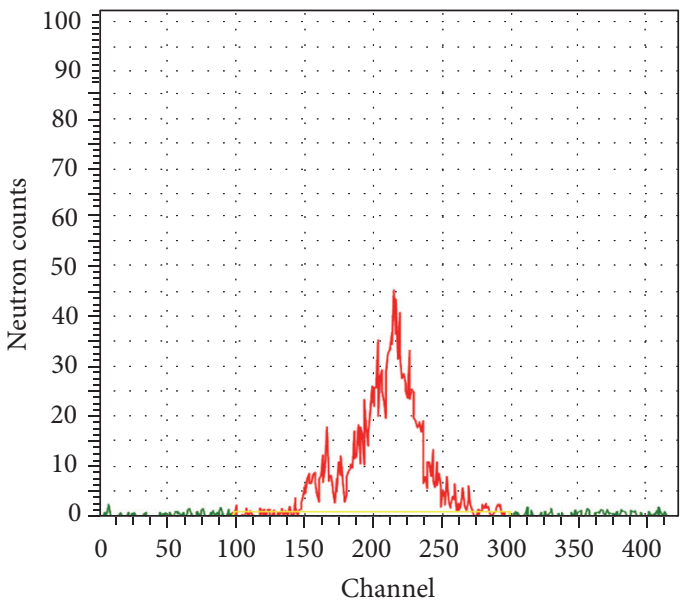

(d)

FIGURE 10: Microstructure of (a) sheet material showing ferritic structure adapted from [29] and (b) rivet material showing martensitic structure adapted from [29] and profile of neutron counts showing shift and peak broadening due to different microstructure in (c) sheet material and (d) rivet.

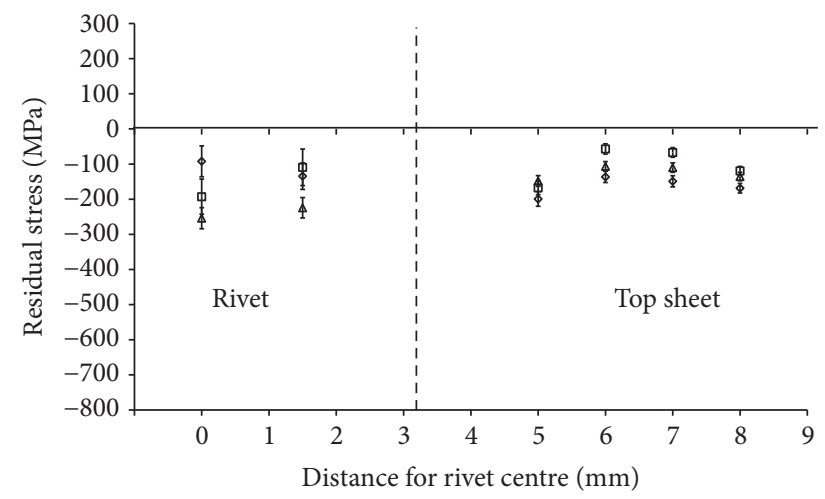

- Normal

- Transverse

$\Delta$ Longitudinal

FIGURE 11: Distribution of residual in the rivet head and top sheet of joint II along FF line as depicted in Figure 5(a).

high magnitude was observed in the rivet leg at $2.5 \mathrm{~mm}$ from the rivet axis (Figure 13). The maximum value of the stress $(-317 \pm 26 \mathrm{MPa})$ was found in the longitudinal direction. A

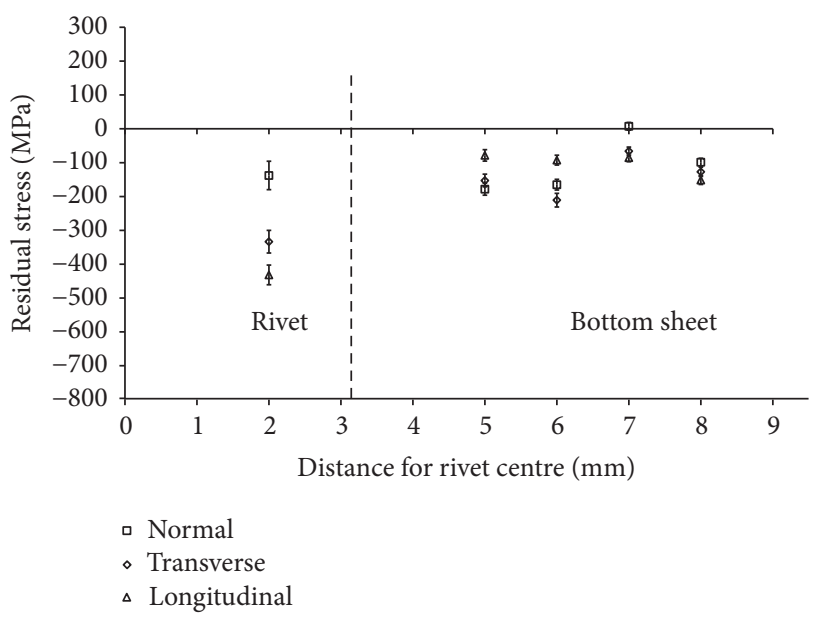

FIGURE 12: Distribution of residual in the bottom sheet and rivet leg of joint II along GG line as depicted in Figure 5(a).

high compressive stress $(-300 \pm 23 \mathrm{MPa})$ was observed at the rivet axis. It was identified from Figure 5(b) that this point ( $0.0 \mathrm{~mm}$ on $\mathrm{HH}$ line) was very near to the boundary between 


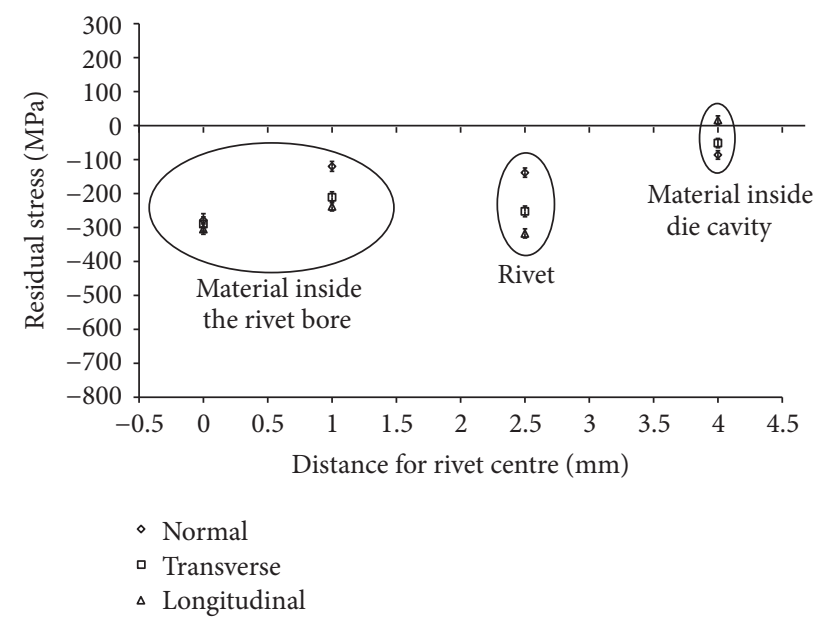

FIGURE 13: Distribution of residual stress in the rivet leg and adjacent sheet material in joint II along HH line as depicted in Figure 5(a).

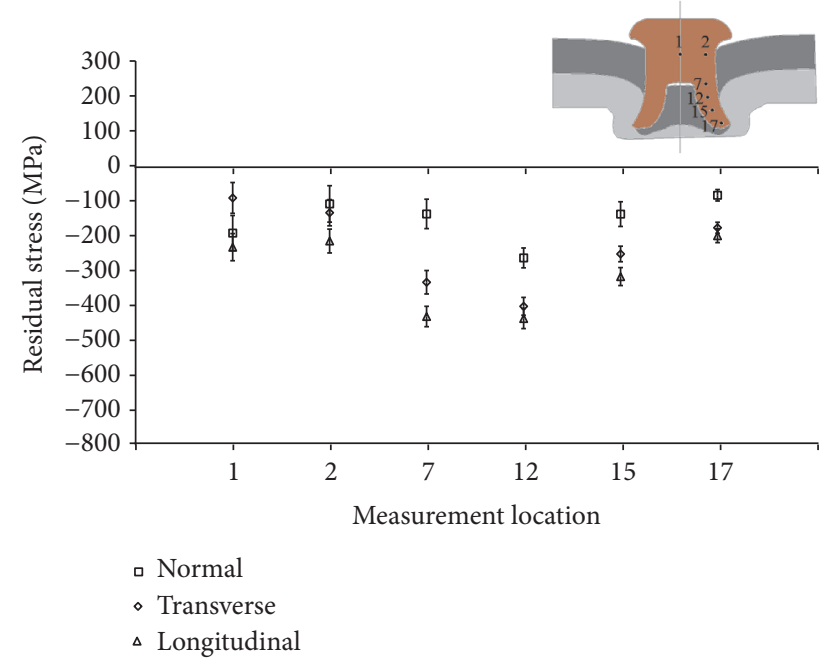

FIGURE 14: Distribution of residual stress in the rivet of joint II.

the top and bottom sheets. Therefore, the material inside the gauge volume was a mixture of the top and bottom sheets. Due to this reason an unexpected high compressive stress was observed at this point. The stress evaluated at $1.0 \mathrm{~mm}$ from the rivet axis on line $\mathrm{HH}$ was compressive as expected. Surprisingly the stress evaluated at $4.0 \mathrm{~mm}$ from rivet axis on line $\mathrm{HH}$ (measurement point 16) was found to be near zero. A tensile stress was expected instead of a zero residual stress, and, in order to identify the reason, the joint was crosssectioned after the neutron measurement. A crack was found in the bottom sheet, as shown in Figure 5(b), which explained the occurrence of the zero residual stress at $4.0 \mathrm{~mm}$ from the rivet axis.

Figure 14 shows the residual stresses inside the rivet at various points. It was clear that the magnitude of the stresses in the rivet head was low. The scale of the stresses increased at points 7 and 12 which were positioned in the leg of the rivet. The compressive stress $(-438 \pm 29 \mathrm{MPa})$ was observed at point 12 in the longitudinal direction. However, the magnitude started to decrease at points 15 and 17 which indicated that a crack had developed inside the rivet. In order to verify this hypothesis, the rivet was extracted from the joint carefully and a crack was observed inside the rivet tip (Figure 15(b)). It should be noted that cross-sectioning of the joint (Figure 5(b)) did not enable the crack inside the rivet to be detected. On the other hand, no crack was observed in the extracted rivet of $1.5 \mathrm{~mm}+1.5 \mathrm{~mm}$ G450 steel joint I (Figure 15(a)). This residual stress (crack inside the rivet tip) also indicated that the joint parameters need to be optimized in order to have a crack-free joint.

Inside the rivet, the overall scale of the residual stress was higher in joint II (-530 $\mathrm{MPa}$ to $-750 \mathrm{MPa})$ compared with joint I (-100 MPa to $-440 \mathrm{MPa})$. The hardness ratio between rivet $(555 \mathrm{HV})$ and sheet materials $(198 \mathrm{HV})$ was 2.8 . As the ratio is higher (compared to 1.78 for previous joint I), the magnitude of the residual stress in the rivet is lower. The low residual stress magnitude in the thick joint II $(2.5 \mathrm{~mm}$ $+2.5 \mathrm{~mm}$ G300 steel joint) compared with the thin joint I (1.5 mm $+1.5 \mathrm{~mm}$ G450 steel joint) can also be linked to the low force gradient at the rivet flaring stage (Figure 2) of the riveting process.

\section{Conclusions}

The novelty of the present study was to characterise the residual stress distribution by neutron diffraction and to make a link between the residual stress distribution and SPR physical events. It is evident from results presented that the neutron diffraction method can successfully quantify residual stress variations in the rivet leg and detect cracking inside the joint (in both rivet tip and sheet material). The neutron diffraction technique enabled a crack in the rivet tip to be detected which was not apparent from the joint cross-section. The stresses evaluated in the rivets were compressive and the scale was higher in the rivet leg compared with the rivet head. In the rivet leg, the compressive residual scale was higher in the thin joint compared with the thick joint because of the comparatively higher gradient of force in the thin joint at the flaring stage of the SPR process and also due to the lower hardness ratio between rivet and sheet material. On the other hand, the residual stresses in the sheets of thick joint were higher when compared with those of thin joint due to the higher gradient of force for thick joint at the bending stage during SPR. The stresses in the bottom sheets were higher than in the top sheets for both joints as the bottom sheet material stretched inside the die cavity. The residual stress distribution presented in this work will be suitable for FEA model validation which can offer an optimum design guidance for different SPR joining conditions, especially for high strength low ductility materials.

\section{Competing Interests}

The authors declare that they have no competing interests. 


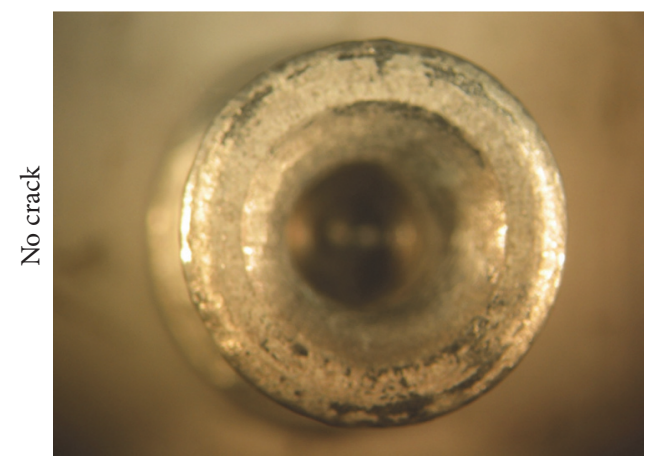

(a)

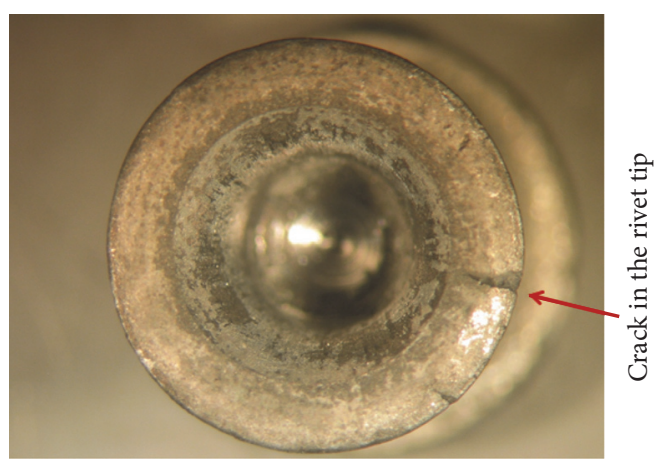

(b)

Figure 15: Extracted rivet showing (a) no crack in rivet of joint I (1.5 + $1.5 \mathrm{~mm}$ G450) and (b) crack in rivet of joint II (2.5 + $2.5 \mathrm{~mm}$ G300).

\section{Acknowledgments}

The authors acknowledge AINSE for awarding Grant no. 2198 to carry out neutron diffraction studies at ANSTO. The authors would like to thank Henrob (UK) Pty Ltd. for supplying the rivets and materials to produce the joints, and also for giving permission to publish this work. The support of CAST CRC and Swinburne University of Technology and the provision of a Ph.D. scholarship are acknowledged. CAST was established under and was supported in part by the Australian Government's Cooperative Research Centre Program.

\section{References}

[1] R. Haque, N. S. Williams, S. E. Blacket, and Y. Durandet, "A simple but effective model for characterizing SPR joints in steel sheet," Journal of Materials Processing Technology, vol. 223, pp. 225-231, 2015.

[2] R. Haque and Y. Durandet, "Strength prediction of self-pierce riveted joint in cross-tension and lap-shear," Materials and Design, vol. 108, pp. 666-678, 2016.

[3] W.-G. Drossel and M. Jäckel, "New die concept for selfpierce riveting materials with limited ductility," Key Engineering Materials, vol. 611-612, pp. 1452-1459, 2014.

[4] X. He, L. Zhao, C. Deng, B. Xing, F. Gu, and A. Ball, "Selfpiercing riveting of similar and dissimilar metal sheets of aluminum alloy and copper alloy," Materials and Design, vol. 65, pp. 923-933, 2015.

[5] X. He, Y. Wang, Y. Lu, K. Zeng, F. Gu, and A. Ball, "Self-piercing riveting of similar and dissimilar titanium sheet materials," International Journal of Advanced Manufacturing Technology, vol. 80, no. 9-12, pp. 2105-2115, 2015.

[6] G. Meschut, V. Janzen, and T. Olfermann, "Innovative and highly productive joining technologies for multi-material lightweight car body structures," Journal of Materials Engineering and Performance, vol. 23, no. 5, pp. 1515-1523, 2014.

[7] P. O. Bouchard, T. Laurent, and L. Tollier, "Numerical modeling of self-pierce riveting - from riveting process modeling down to structural analysis," Journal of Materials Processing Technology, vol. 202, no. 1-3, pp. 290-300, 2008.
[8] M. Grujicic, J. Snipes, S. Ramaswami, and F. Abu-Farha, "Process modeling, joint-property characterization and construction of joint connectors for mechanical fastening by selfpiercing riveting," Multidiscipline Modeling in Materials and Structures, vol. 10, no. 4, pp. 631-658, 2014.

[9] R. Porcaro, A. G. Hanssen, M. Langseth, and A. Aalberg, "The behaviour of a self-piercing riveted connection under quasistatic loading conditions," International Journal of Solids and Structures, vol. 43, no. 17, pp. 5110-5131, 2006.

[10] X. Sun and M. A. Khaleel, "Performance optimization of selfpiercing rivets through analytical rivet strength estimation," Journal of Manufacturing Processes, vol. 7, no. 1, pp. 83-93, 2005.

[11] G. Di Franco, L. Fratini, A. Pasta, and V. F. Ruisi, "On the self-piercing riveting of aluminium blanks and carbon fibre composite panels," International Journal of Material Forming, vol. 6, no. 1, pp. 137-144, 2013.

[12] R. Khezri and A. Melander, "Simulation of self piercing riveting of TRIP800 sheet steel in $1+1 \mathrm{~mm}$ thickness," IM-2003-515, Swedish Institute for Metals Research, 2003.

[13] J. Gårdstam, "Simulation of self piercing riveting of high strength austenitic stainless steel in 1 and $2 \mathrm{~mm}$ sheet thickness," IM-2004-537, Swedish Institute for Metals Research, 2004.

[14] R. Khezri and A. Melander, "New technology for self piercing riveting of TRIP800 in $1+1$ and $1+2 \mathrm{~mm}$ sheet thickness," Tech. Rep. IM-2003-545, Swedish Institute for Metal Research, 2003.

[15] E. Sjöström, J. Gårdstam, and R. Trinick, "Development of martensitic stainless steel rivets for applications of self piercing riveting of stainless steel sheets," in IM-2004-536, Swedish Institute for Metals Research, 2004.

[16] D. Li, L. Han, M. Thornton, and M. Shergold, "Influence of rivet to sheet edge distance on fatigue strength of self-piercing riveted aluminium joints," Materials Science and Engineering A, vol. 558, pp. 242-252, 2012.

[17] Z. Jin and P. K. Mallick, "Enhancement of fatigue life of selfpiercing riveted joints by coining," in Proceedings of the ASME International Mechanical Engineering Congress and Exposition (IMECE '02), vol. 17, pp. 417-429, New Orleans, La, USA, 2002.

[18] L. Han, K. W. Young, A. Chrysanthou, and J. M. O'Sullivan, "The effect of pre-straining on the mechanical behaviour of selfpiercing riveted aluminium alloy sheets," Materials and Design, vol. 27, no. 10, pp. 1108-1113, 2006. 
[19] L. Huang, Y. Shi, H. Guo, and X. Su, "Fatigue behavior and life prediction of self-piercing riveted joint," International Journal of Fatigue, vol. 88, pp. 96-110, 2016.

[20] X. Zhang, X. He, B. Xing et al., "Influence of heat treatment on fatigue performances for self-piercing riveting similar and dissimilar titanium, aluminium and copper alloys," Materials and Design, vol. 97, pp. 108-117, 2016.

[21] X. He, I. Pearson, and K. Young, "Self-pierce riveting for sheet materials: state of the art," Journal of Materials Processing Technology, vol. 199, no. 1, pp. 27-36, 2008.

[22] R. Haque, J. H. Beynon, Y. Durandet, O. Kirstein, and S. Blacket, "Feasibility of measuring residual stress profile in different selfpierce riveted joints," Science \& Technology of Welding \& Joining, vol. 17, no. 1, pp. 60-68, 2012.

[23] R. Haque, J. Beynon, O. Kirstein, Y. C. Wong, and Y. Durandet, "Evaluation of residual stress in SPR joint by neutron diffraction," Advanced Materials Research, vol. 409, pp. 575-580, 2012.

[24] R. Haque, Residual Stress and Deformation in SPR Joints of High Strength Materials, Swinburne University of Technology, 2014.

[25] R. Haque, Y. C. Wong, A. Paradowska, and Y. Durandet, "Residual stress profiles in riveted joints of steel sheets," Science and Technology of Welding and Joining, vol. 20, no. 3, pp. 199207, 2015.

[26] Bluescope, http://steelproducts.bluescopesteel.com.au/home/steelproducts/metallic-coated-steel.

[27] R. Haque, J. H. Beynon, and Y. Durandet, "Characterisation of force-displacement curve in self-pierce riveting," Science and Technology of Welding and Joining, vol. 17, no. 6, pp. 476-488, 2012.

[28] J. A. James and L. Edwards, "Application of robot kinematics methods to the simulation and control of neutron beam line positioning systems," Nuclear Instruments and Methods in Physics Research, Section A: Accelerators, Spectrometers, Detectors and Associated Equipment, vol. 571, no. 3, pp. 709-718, 2007.

[29] R. Haque, Y. Durandet, Y. C. Wong, A. Paradowska, J. H. Beynon, and S. Blacket, "Optimising parameters for meaningful measurement of residual strain by neutron diffraction in selfpierce riveted joints," Science and Technology of Welding and Joining, vol. 18, no. 6, pp. 492-499, 2013.

[30] T. Lorentzen, M. Hutchings, P. Withers, and T. Holden, Introduction to the Characterization of Residual Stress by Neutron Diffraction, Taylor \& Francis, Boca Raton, Fla, USA, 2005.

[31] E. D. Doyle, Y. C. Wong, and M. I. Ripley, "Residual stress evaluation in martensitic stainless steel as a function of gas quenching pressure using thermal neutrons," Physica B: Condensed Matter, vol. 385-386, pp. 897-899, 2006. 

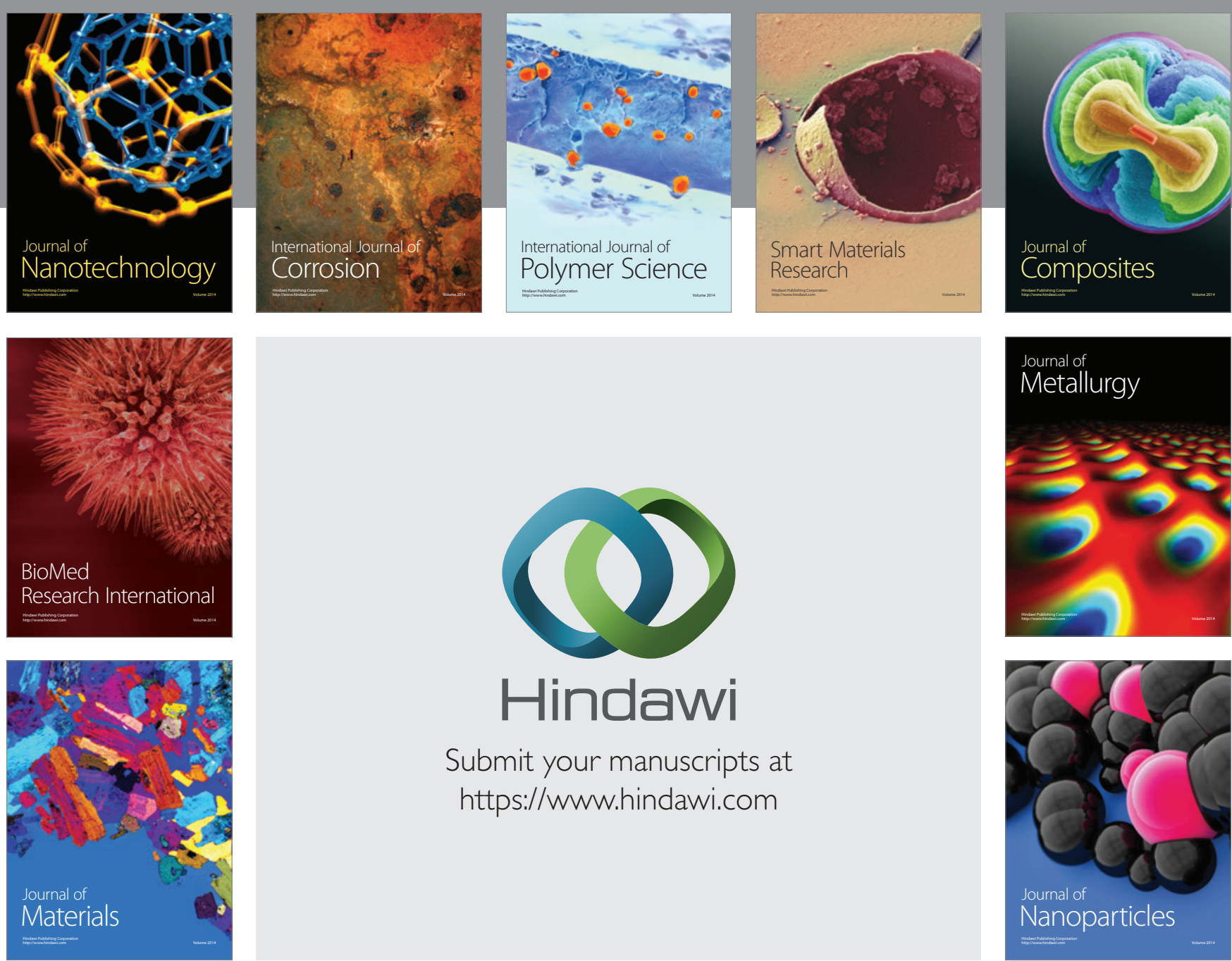

\section{Hindawi}

Submit your manuscripts at

https://www.hindawi.com

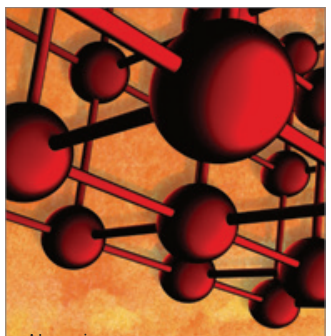

Materials Science and Engineering
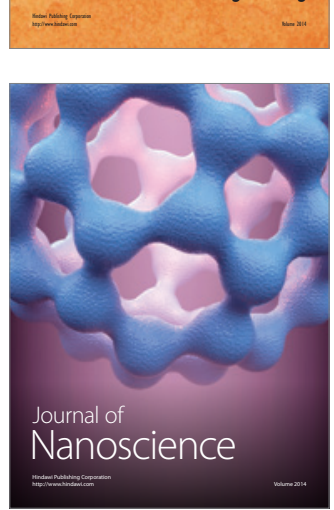
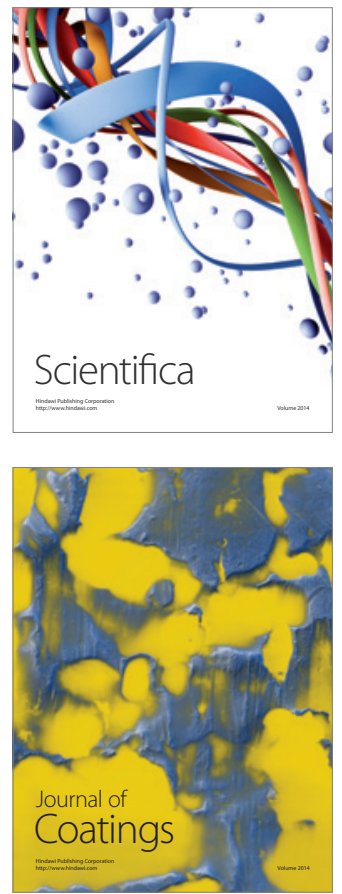
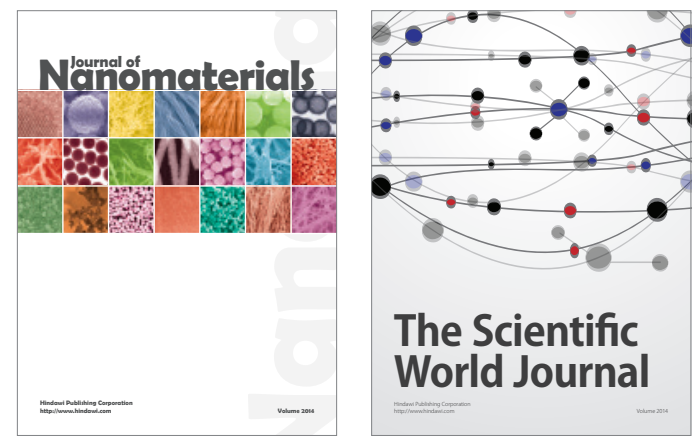

The Scientific World Journal
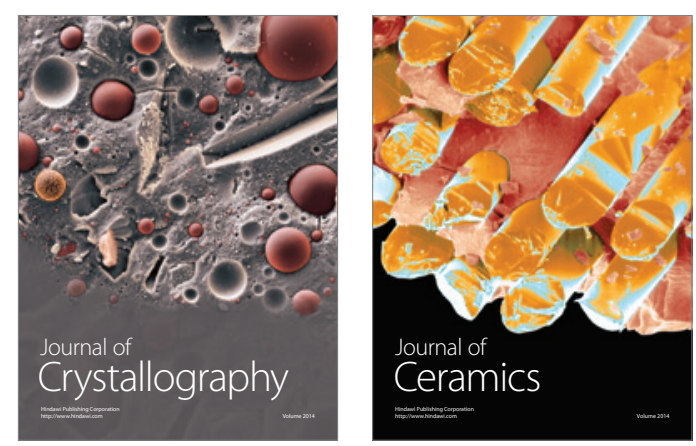
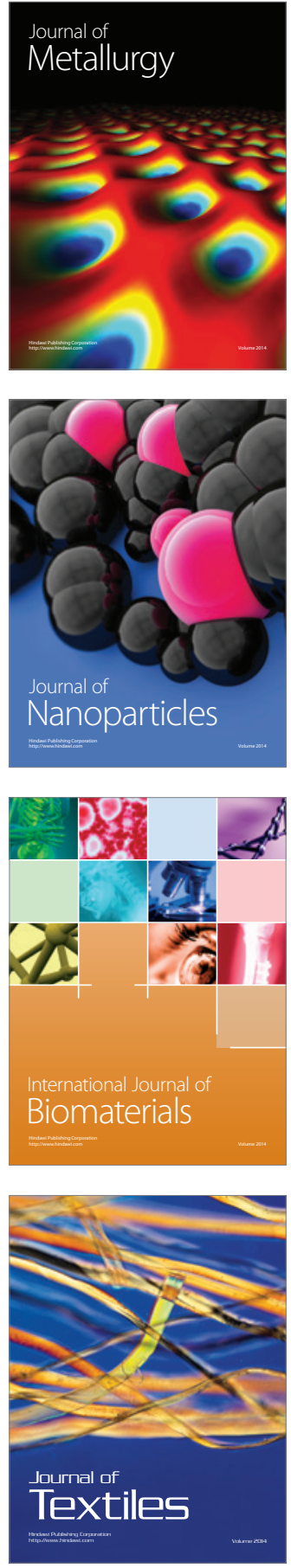